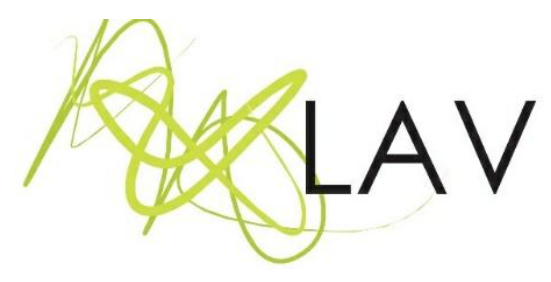

\title{
Formação audiovisual e identidade indígena na produção de cinema e vídeo com os povos Potiguara e Anacé
}

\author{
Audiovisual training and indigenous identity in film and video production with the \\ Potiguara and Anacé peoples
}

Iago Barreto Soares

Instituto Federal do Ceará

José Albio Moreira de Salesii

Universidade Estadual do Ceará / Instituto Federal do Ceará

\begin{abstract}
Resumo
Este artigo tem por objetivo relatar duas experiências de formação com os povos Potiguara e Anacé, que focalizaram o trabalho com identidade indígena, cinema e produção audiovisual. Para a realização das experiências formativas, parte-se do pressuposto de que a produção de imagens interfere na identidade étnica de povos indígenas e que é possível, nesse processo, promover atividades de autorreconhecimento de identidades étnicas. Para o relato, toma-se por base os conceitos dos povos do Nordeste de Bartolomé (2006), as ideias de tradição de Hobsbawm (2008), de cultura brasileira de Bosi (1992), bem como as de cinema e audiovisual de Lyra (2005).
\end{abstract}

Palavras-Chave: cinema indígena, anacé, potiguara, etnogênese.

\begin{abstract}
This text aims to report two training experiences with the Potiguara and Anacé peoples, in which they sought to work with indigenous identity, cinema and audiovisual production. For the realization of the formative experiences, we start from the assumption that the production of images interferes in the ethnic identity of indigenous peoples and that it is possible in this process to promote activities of self-recognition of ethnic identities. For the report we take as a base the concepts of identity in the postmodernity of Stuart Hall (1992), the question of the ethnogenesis of the peoples of the Brazil's northeast of Bartolomé (2006), the ideas of tradition by Hobsbawm (2008), of Brazilian culture by Bosi (1992), and cinema and audiovisual Lyra (2005).
\end{abstract}

Key-Word: indigenous cinema, anacé, potiguara, ethnogenesis.

Enviado em: 08/03/21 - Aprovado em: 21/04/21

\section{Introdução}

Uma das tarefas do educador ou educadora progressista, através da análise política, séria e correta, é desvelar as possibilidades, não 
importam os obstáculos, para a esperança, sem a qual pouco podemos fazer porque dificilmente lutamos, e quando lutamos, enquanto desesperançados ou desesperados, a nossa é uma luta suicida, é um corpo a corpo puramente vingativo (FREIRE, 2020, p. 9).

As primeiras imagens indígenas produzidas no Brasil remontam ao processo de colonização. As mais antigas que temos registro são dos Tarairius e Tupis, realizadas por Albert Eckhout, pintor da comitiva de Maurício de Nassau, que aqui trabalhou entre 16371644 (COSTA, 2011). Essas imagens refletiam uma visão eurocêntrica, como a maioria produzida sobre povos originários das América até o século XIX. Tais imagens, ao invés de contribuir para a formação das identidades indígenas, colaboram para o não reconhecimento da diversidade étnica e cultural e favorecem processos que resultam em visões estereotipadas dos indígenas.

Nossa aproximação com essa problemática, bem como as aproximações com grupos de etnias que lutam pelo reconhecimento de suas culturas, levou-nos a pensar formas de intervir em processos de produção de imagens da identidade indígena. Assim, passamos a trabalhar com formações de indígenas que utilizam o audiovisual para o fortalecimento dessas identidades, sendo objetivo deste relato apresentar nossa experiência com os povos Potiguara e Anacé.

Sob esse aspecto, nossa partilha de experiência com o ensino de audiovisual em aldeias indígenas do Ceará, um estado cuja imagem poética, ao longo de sua história, tem sido associada à lenda da índia Iracema e do guerreiro branco Martim Soares Moreno, se justifica pela necessidade de tornar evidente a necessidade de políticas sociais e de desenvolvimento que possam valorizar as identidades étnicas indígenas locais, as quais lutam por reconhecimento e afirmação de suas culturas, bem como pela demarcação de suas terras.

Para este relato, elegemos como recorte duas experiências de formações, realizadas entre 2018 e 2019, ofertadas para povos da reserva indígena Taba dos Anacé, no município de Caucaia, assim como na aldeia Viração dos Potiguara, no município de Tamboril. 0 material produzido nas formações resultou em dois vídeos denominados: Uma aldeia Chamada Viração e Taba dos Anacé. Vale ressaltar que nosso trabalho é parte de experiências pioneiras de formação em audiovisual com povos indígenas no Ceará e destaca-se principalmente pelo viés de formar, compondo-se na e com cultura e identidade indígena. Isto significa que o processo de aprendizagem é recíproco entre os participantes e aqueles que promovem as formações. Para que se possa entender essa perspectiva de 
trabalho, faz-se necessário esclarecermos o que entendemos por cinema indígena, como também a sua relação com a identidade.

\section{Identidade, cinema e audiovisual indígena}

Antes de iniciarmos o relato propriamente dito, começaremos nossa narrativa esclarecendo o que compreendemos por identidade, conceito que é visto pelos antropólogos e sociólogos a partir de duas dimensões: a pessoal e a social. Embora tais dimensões estejam diretamente relacionadas, é possível perceber que elas são efetivadas em níveis diferentes.

Nessa perspectiva, a dimensão pessoal funciona como base para a construção da identidade de grupo, seja no sentido étnico, social ou profissional. Isto quer dizer que a identidade pessoal é relacional, já que para se estabelecer o eu, precisamos determinar as diferenças em relação ao outro. É importante ressaltar que, nessa diferenciação, são utilizados como parâmetros elementos biológicos, culturais, bem como quaisquer outros que possam distinguir as diferenças entre o eu e os outros em um processo de interação social (BRAGA, 2005).

Queremos dizer com isso que a identidade de um grupo étnico tem que ser vista como parte da formação de identidade nacional. A partir dessa compreensão, dialogamos com as ideias e as concepções de cultura de Alfredo Bosi (1992, p. 6), para o qual não existe "uma cultura brasileira homogênea, matriz dos nossos comportamentos e dos nossos discursos". Para Bosi (1992), somente assim podemos entender o caráter plural da cultura no Brasil, sendo esse o passo decisivo para que possamos compreendê-la como o "resultado de um processo de múltiplas interações e oposições no tempo e no espaço" (BOSI, 1992, p. 7).

No diálogo com as ideias de Alfredo Bosi, embasamos nossa premissa de compreensão da cultura brasileira como uma cultura plural, composta por diferentes etnias e particularidades. Por meio dessa premissa, torna-se possível nos lançarmos no universo cultural indígena e na construção do enquadramento de nosso olhar, com e para a construção de imagens significativas das identidades dos povos Potiguara e Anacé.

Feitos tais esclarecimentos, é fundamental elucidar o que compreendemos por cinema e audiovisual. De uma forma simplificada, podemos dizer que cinema e audiovisual são parte da produção de imagem em movimento, na medida em que o resultado de ambos pode ser lido como uma produção audiovisual. Não queremos com isso ignorar as 
discussões acadêmicas sobre o assunto, dentre elas a de Bernadete Lyra (2005) em Cinema e audiovisual: cinco anotações, que discute as convergências e divergências dos dois conceitos e admite que, ao tentarmos estabelecer relações entre cinema e audiovisual, necessitamos de uma série de acomodações teóricas. Porém, em suas conclusões, Lyra (2005, p. 12) admite que o conceito de cinema pode ser alargado na "pluralidade epistemológica das materialidades" que o cercam no que se refere à instituição cinematográfica. Para a autora, o que normalmente compreendemos por cinema é o resultado de uma 'perversa mistura' entre a indústria de filmes e as estratégias de combinação de imagens em movimento e sons.

Portanto, essas definições de identidade, cultura brasileira e de audiovisual e cinema podem esclarecer o nosso modo de ver e buscar interferir em processos de formação da identidade indígena a partir do audiovisual. Acreditamos que elas são fundamentais para que o leitor entenda nosso ponto de partida e de chegada, com base em nosso relato.

Nesse sentido, consideramos importante trazer à tona mais algumas considerações sobre produção audiovisual e identidades indígenas da atualidade, que possuem vínculo com os processos criados pela mídia e com a construção do olhar da mídia sobre o sujeito e a identidade indígena. Sob esse aspecto, elas reforçam as imagens que temos sobre o indígena, pois, muito do contato que as pessoas não indígenas têm com os povos é via mídia. Dessa maneira, vemos a mídia como um campo de batalha para a afirmação étnica, por isso, neste trabalho, atentamos para a questão do cinema e do vídeo como processo midiático.

De acordo com Silva (2020, p. 48), em seu trabalho sobre o índio no Cinema Brasileiro, muito do imaginário que a nossa sociedade construiu sobre o índio no cinema tem como referência "não o índio real, mas aquele construído pela literatura romântica", que, portanto, são tipos "marcadamente idealizados".

Desse modo, o cinema indígena surge como uma alternativa à construção colonizadora, ao oferecer aos povos indígenas a possibilidade de contrapor as produções de imagens do invasor, ao mesmo tempo em que constroem a imagem de seus cotidianos e culturas por meio do acesso às novas mídias de produção e consumo de imagens.

Esse movimento retoma elementos de um processo de antropofagia, no qual as armas do inimigo são utilizadas para o fortalecimento e vitalidade da luta por protagonismo cultural e construção da autoimagem dos povos indígenas. De acordo com Ribeiro: 
No plano racial, o ethos colonialista se configura como uma justificativa da hierarquização racial, pela introjeção no índio, no negro e no mestiço de uma consciência mistificada de sua subjugação. Por ela se explica o destino das camadas subalternas por seus caracteres raciais e não pela sua exploração de que são vítimas. Deste modo, o colonialismo não só impera, mas também se autodignifica, ao mesmo tempo em que subjuga o negro, o índio e seus mestiços e degrada sua autoimagem étnica. Além de despersonalizados - porque convertidos em mera condição material da existência do estrato dominador - as camadas subalternas são alienadas no mais recôndito de suas consciências pela associação da cor 'escura' com o sujo e da 'branca' como limpo (RIBEIRO, 1979, p. 83).

Essa concepção de cinema indígena como mídia significa, para esses povos, do ponto de vista da construção de sua autoimagem, uma das promoções culturais que potencializam o seu encontro com a possibilidade de ressignificar a cultura local. A linguagem audiovisual promove neles uma espécie de libertação para elaborar as suas narrativas. Outro fator que colabora para a adoção do registro audiovisual é a cultura dominante entre os indígenas, ou seja, a cultura da oralidade e corporeidade como parte de seus cotidianos. Assim, a linguagem audiovisual promove a simbiose entre mídia e realizadores de forma singular. Nesse sentido,

[c]om a expansão de filmes e vídeos realizados por cineastas e coletivos indígenas a partir das possibilidades incentivadas pelo projeto Vídeo Nas Aldeias e outras iniciativas, é possível vislumbrar um processo de constituição de um modo de fazer cinema que pode ser agrupado enquanto categoria de cinema indígena. De forma ampliada, constitui-se um autêntico mosaico de possibilidades que subvertem uma lógica de produzir narrativas historicamente calcadas em uma visão eurocentrada (COSTA; GALINDO, 2018, p. 37).

O mosaico de possibilidades e a emergência política fazem do processo de realização audiovisual indígena uma forma de quebrar barreiras entre ficção e documentário, aproximando as realizações à performance e à videoarte. Com essas aproximações, a ideia de um cinema indígena é um processo em formação constante; que mesmo utilizando da gramática clássica do cinema, possui suas singularidades, especialmente pelo seu papel político, conforme descreve Krenak:

Com muitos narradores indígenas animados em contar histórias de diferentes lugares, continua no ar. Alguém de qualquer lugar no mundo pode abrir e ver uma menina tukano contando a história da tia dela na roça cultivando diferentes tipos de maniwa, fazendo beiju e mostrando uma culinária fantástica, rica, tirada da natureza, tirada da terra. Mostrar ritos, mostrar festas, mostrar potências de vida de diferentes lugares daqui dessa banda do mundo (KRENAK, 2017, p. 30). 
É importante ressaltar que as histórias contadas pelos indígenas não possuem o mesmo ritmo que as do cinema norte-americano ou europeu, já que estes trabalham com uma linguagem cinematográfica conhecida pelo grande público. As histórias dos indígenas possuem um ritmo que envolve uma escuta e determinados signos, tempos e temáticas próprias dos povos nativos. Além de um papel político específico, as narrativas estão permeadas por mensagem sobre ecologia, convivência e respeito entre sociedade, mesmo que tais aspectos e temáticas não sejam necessariamente o tema dos filmes.

Discorrendo sobre o assunto, Krenak (2017) afirma que as novas tecnologias facilitam a difusão da cultura indígena, mas não estão conseguindo o que considera essencial: educar o olhar das pessoas para essas imagens e sons, para que tais mensagens falem ao coração, possibilitando ao espectador não indígena entender e ter empatia com essas causas, assim como se relacionar com elas em forma de diálogo.

É como se a gente estivesse trabalhando com uma estética do excesso. Excesso de texto, excesso de imagem, excesso de informação, de som, chapando tudo. E pouca reflexão, tempo para ouvir, pensar, ler. No sentido de viver, não só de olhar. A recepção dessas mensagens, dessa comunicação, é essencial. Só a emissão não é o suficiente. É preciso de recepção. Alguém do outro lado ouvindo essa canção é necessário (KRENAK, 2017, p. 30).

Na opinião de Krenak, precisamos com urgência realizar essa aproximação entre o cinema indígena e o espectador usual de cinema, já acostumado com a linguagem comercial. Postas essas considerações sobre o que compreendemos por cinema indígena, trataremos, no tópico seguinte, sobre as experiências de cinema indígena no Ceará.

\section{Cinema indígena no Ceará}

As experiências com produção e reflexão sobre cinema indígena no Ceará ainda são pouco significativas do ponto de vista teórico e prático, especialmente no campo da pesquisa acadêmica. Existem algumas poucas formações autônomas, como as que relatamos neste artigo. Porém, mesmo com essa lacuna, existe um projeto de formação indígena em audiovisual, chamado Escola de Cinema Indígena Jenipapo-Kanindé. A iniciativa funciona desde 2018, na qual um dos autores trabalhou em vários núcleos de comunicação, inclusive com outros povos, como os Tapeba, a partir da Articulação da Juventude Indígena Tapeba (AJIT) e os Kanindé, por meio da Mídia Kanindé. Atualmente, a Mídia Kanindé, além de vídeos, produz fotografia, rádio comunitária e outros produtos. 
Feitas as considerações sobre cinema indígena no Ceará, passamos ao foco central deste artigo que tem como objetivo relatar a nossa experiência em formação audiovisual e cultura indígena, na produção do curta Uma Aldeia chamada Viração (2018), de Letícia Potyguara, e o média Taba dos Anacé (2019), trabalhos realizados coletivamente pela juventude Anacé da Reserva. Esses dois produtos audiovisuais foram precedidos por uma formação de jovens indígenas em seus territórios.

O critério que utilizamos para o recorte das duas experiências, está relacionado a reflexões sobre formação e cultura indígena dos autores. As duas experiências traduzem possibilidades significativas da formação audiovisual vivenciada no contexto da afirmação de identidade indígena, produção de cinema e vídeo no Ceará.

Na formação, trabalhamos com crianças e jovens indígenas das duas etnias (Anacé e Potiguara), limitando como público-alvo jovens até 22 anos. Trabalhamos com uma metodologia participativa, composta por oficinas e conversas sobre o processo. A participação envolveu diferentes segmentos da comunidade, incluindo as lideranças da aldeia, as quais são responsáveis pela aprovação da nossa permanência e realização das atividades na localidade.

Vale salientar que todo o processo foi registrado em vídeo. Desse modo, o presente trabalho pretende relatar a experiência da formação em audiovisual e de como a referida formação interferiu positivamente no processo de afirmação étnica e na construção de memória dos povos indígenas do Ceará em suas singularidades perante povos de outros estados e regiões.

Para compreendermos o processo, faz-se necessário trazermos um pouco do contexto da resistência indígena do Ceará e de como se dá a produção imagética sobre os povos ameríndios. O estado do Ceará conta, atualmente, com 15 povos indígenas (14 reconhecidos e um em processo de reconhecimento ${ }^{1}$ ), todos com forte grau de aproximação com os centros urbanos, ou com aldeias inseridas nos próprios centros urbanos. O processo de colonização específico da região fez com que nenhum desses povos conseguisse manter sua língua tradicional. Esse mesmo processo também foi responsável por uma forte miscigenação entre os próprios povos e com a população negra e branca.

No Ceará, o processo de produção de imagem e identidade indígena seguiu o mesmo modelo geral do restante do país. A particularidade que merece destaque é a

\footnotetext{
${ }^{1}$ O povo Karão Jaguaribara, citado acima, já foi reconhecido pela Federação dos Povos e Organizações Indígenas do Estado do Ceará (FEPOINCE), e estão, até o presente momento, tentando o reconhecimento junto ao Estado brasileiro.
} 
grande miscigenação, citada anteriormente, que contribui para o seu não reconhecimento oficial e, portanto, para a sua condição de indigente na perspectiva do colonizador. Tal perspectiva criou o estereótipo de "identidade indígena a partir de um olhar eurocêntrico, criando na diversidade étnica das Américas o signo do índio" (WERÃ, 2019, p. 76), estereótipo este que tenta amontoar uma série de povos, línguas, territórios de uma maneira simplificada.

Destaca-se também que, para parte da população urbana cearense, ainda perdura a ideia de que um indígena é apenas aquele que vive nu no meio da mata, ignorando o processo colonizatório substancial que ocorreu e ainda ocorre em zonas onde a invasão se deu primeiro.

Buscando alternativas para superar tal ideia sobre o indígena, algumas lideranças recorrem a processos de identidade cultural, que envolvem as tradições indígenas como elementos de fortalecimento de sua identidade étnica. Um desses recursos é a restauração e significação de rituais do cotidiano indígena, tomando como ponto de partida a perspectiva da etnogênese. Essa perspectiva, por seu turno, é parte do esforço que visa promover

[o] ressurgimento de grupos étnicos considerados extintos, totalmente 'miscigenados' ou 'definitivamente aculturados' e que, de repente, reaparecem no cenário social, demandando seu reconhecimento e lutando pela obtenção de direitos ou recursos (BARTOLOMÉ, 2006, p. 39).

Compreendendo que a tradição é também uma invenção, as lideranças utilizam elementos simbólicos, a exemplo do ritual do toré, a medicina tradicional, cantos e outros aspectos culturais, como parte do fortalecimento das identidades dos indígenas no Ceará. Entendem as lideranças que essas tradições são elementos que precisam ser trazidos para o campo da luta política pela demarcação de terras.

Sobre essa ideia de tradição como invenção ou tradição inventada, recorremos a Hobsbawm que afirma:

Por Tradição inventada entende-se um conjunto de práticas, normalmente reguladas por regras tácitas ou abertamente aceitas; tais práticas, de natureza ritual ou simbólica, visam inculcar certos valores e normas de comportamento através da repetição, o que implica automaticamente uma continuidade em relação ao passado. Aliás, sempre que possível, tenta-se estabelecer continuidade em relação a um passado histórico apropriado (HOBSBAWM, 2008, p. 9). 
Partindo dessa ideia de tradição como invenção, os povos indígenas do Ceará retomam tradições silenciadas, tanto para dar força espiritual à sua luta, como para ajudar no reconhecimento da sua memória coletiva enquanto povo tradicional. Já que, em sua maioria, não possuem o fenótipo dito indígena e necessitam desses rituais comuns que criam para se reconhecerem.

Práticas como a retomada da feitura de cocares representam a criação de uma identidade diferenciada diversa e em constante mudança, dentro de um contexto de pósmodernidade. Segundo Hall (2015, p. 13), "a identidade plenamente unificada, completa, segura e coerente é uma fantasia".

Após essa contextualização de aspectos do cinema indígena no Ceará, bem como dos problemas enfrentados nos processos de trabalho com a cultura indígena, em função sobretudo da superação das questões identitárias pela miscigenação experimentada pelos grupos étnicos locais, passamos, no tópico seguinte, a relatar nossa experiência nas formações com audiovisuais e identidade cultural indígena.

\section{Encontros em Uma aldeia Chamada Viração}

A primeira experiência aconteceu com o documentário Uma aldeia Chamada Viração, de Letícia Potyguara². Em 2018, já havíamos promovido formações em vídeo e fotografia em várias aldeias da zona metropolitana de Fortaleza, e esperávamos uma oportunidade de expandir o trabalho para os povos indígenas do Sertão do Ceará. Sabendo que a Assembleia Estadual dos Povos Indígenas do Ceará ocorreria em dezembro de 2018 no município de Tamboril, mais precisamente na aldeia Viração do povo Potiguara, aproveitamos o evento para propor à liderança Eliza Potiguara uma formação em forma de oficina, para que os jovens de seu povo produzissem um documentário, com a finalidade de apresentar a sua aldeia aos demais povos que viriam para a Assembleia.

Dez dias antes do evento, chegamos à aldeia. Contando com a mediação de Lucas Potiguara, uma jovem liderança daquele povo, fomos apresentados à juventude local, que seria a turma da formação em vídeo. A turma era composta por crianças e jovens de até 13 anos de idade, com exceção de Lucas, um adolescente de mais de 15 anos. Vale ressaltar que a aldeia Viração só possui escola de Ensino Fundamental, o que obriga os

2 Letícia assina seu nome Potyguara com a letra Y por uma questão pessoal e política. 
jovens potiguaras a mudarem para o município de Tamboril, caso desejem cursar o Ensino Médio.

Desse modo, embora o trabalho de Lucas fosse organizar a turma, foi Letícia, a mais velha dentre os outros alunos, com 13 anos, que assumiu a liderança do projeto. Em relação ao número de participantes na formação, podemos dizer que tivemos um número variável de alunos, entre 8 (oito) e 15 (quinze) por aldeia. Atribuímos esse número ao fato de grande parte das outras crianças estarem ajudando os adultos em outras atividades da organização do evento.

Embora nosso método de ensino seja, de certo modo, um método intuitivo, partimos de experiências com ONGs e com outros projetos. Por meio das pesquisas, percebemos similaridades entre nosso trabalho e outras experiências, a exemplo a de Juliano José de Araújo. No artigo Práticas fílmicas do projeto Vídeo nas Aldeias, o autor descreve seu processo de trabalho, afirmando que

[a] rotina diária de trabalho das oficinas consiste, basicamente, na captação do material audiovisual pelos alunos na parte da manhã e posterior exibição na aldeia à tarde. Inicialmente, os coordenadores da oficina ensinam aos indígenas o manejo básico da câmera, orientando-os a fazer o foco manual e o balanço de branco. Na hora que eles dominaram essas duas coisinhas, já começam a trabalhar fazendo exercícios. O exercício que a gente tem costume de dar é esse de filmar o cotidiano de alguém (ARAúJo, 2014, p. 27).

Em um processo de trabalho semelhante, tínhamos, durante parte da manhã, conversas teóricas sobre linguagem cinematográfica; durante a tarde, realizávamos os 'exercícios', com temáticas que agrupamos em duas categorias: a primeira era composta de registros de atividades da aldeia relacionadas com o seu cotidiano, que podiam ser desde um plantio até uma partida de futebol, e a segunda era a realização de entrevistas com moradores da Viração.

Vale registrar a facilidade de condução da primeira categoria, talvez pelo fato de não depender de uma preparação para se colocar ou colocar alguém diante da câmera. Já o processo de entrevistas foi um trabalho mais difícil, pois exigia do aluno um posicionamento em relação à filmagem, bem como uma ajuda para que a pessoa entrevistada pudesse se posicionar adequadamente diante da câmera. Além desses detalhes técnicos, era necessário que se pensasse antes acerca do que perguntar, e buscar meios de superação da timidez, tão presente entre crianças e adolescentes indígenas.

A questão do posicionamento de câmera veio com a linguagem; o da timidez foi se resolvendo com o tempo e o entrosamento da equipe, no qual destacamos, novamente, o 
trabalho de Letícia como líder, ajudando-nos a fazer os questionamentos, tanto ao seu grupo da formação, quanto ao seu povo, tornando possível que pessoas tímidas, como Maria Clara Potiguara, conseguissem se destacar na captação de som.

Os questionamentos se deram em dois sentidos: i) o que o grupo queria saber sobre o seu povo, e ii) o que o grupo queria mostrar do seu povo para as pessoas que estavam vindo para a Assembleia Estadual. Dos questionamentos surgiu o título do filme: Uma Aldeia Chamada Viração. As perguntas aos anciãos giravam em torno do porquê a aldeia ter esse nome e quando ela foi fundada. Perguntou-se também sobre as histórias e lendas envolvendo o rio de sangue, no qual vários Potiguara foram mortos em massacres. Segundo essas lendas, o sangue deles está na água que alimenta a aldeia ${ }^{3}$.

Nessa formação e produção, seguimos uma linha de trabalho muito próxima da produção de Nunes, Silva e Silva (2014), que foi relatada no artigo Cinema indígena: de objeto a sujeito da produção cinematográfica no Brasil, no projeto Cineastas Indígenas da ONG Vídeo nas Aldeias, denominada pelos autores como um dispositivo teórico e metodológico a ser multiplicado e transformado. Tomando essa experiência como referência para a nossa formação e produção de Uma Aldeia Chamada Viração, podemos afirmar que a perspectiva experimentada foi a de construir uma contra-narrativa, pois, de acordo com os autores, esse tipo de filme carrega consigo o potencial de funcionar como contra-narrativa. São, portanto,

[...] um conjunto de representações capaz de confrontar a coleção de imagens estereotipadas produzidas até então nacionalmente, e de trazer as narrativas dos diferentes grupos indígenas para 0 presente histórico, dando visibilidade às suas culturas e lutas, ao mesmo tempo em que operam como um discurso de reelaboração de suas identidades, passíveis de produção de novos significados (NUNES; SILVA; SILVA, 2014 p. 189).

Além desse aspecto de dispositivo teórico metodológico, no sentido de fortalecer a identidade indígena dos povos da aldeia Viração, foram inseridos no filme dois momentos particulares do que poderia ser chamado de performance ou "o sujeito que filma, agora habitando a cena, que se ficcionaliza, fazendo sua autorrepresentação" (SANT'ANA, 2018, p. 66). O primeiro é o momento no qual Lucas Potiguara pinta Tainá com tinta vermelha, em um dos pontos importantes da aldeia, um dos olhos d'água; o segundo ocorre ao final do filme, quando a diretora Letícia, junto de outros participantes tentam lembrar as músicas do toré de sua aldeia. Esses dois momentos, portanto, dão ao filme o tom de não ser só um documento, mas também uma ficcionalização do que, de fato, é real: a aldeia.

\footnotetext{
${ }^{3}$ Como dito no filme, a Aldeia Viração é conhecida por ser uma aldeia no meio do sertão cearense em que as fontes de água ou olhos d'água nunca secam, fazendo dessa água algo sagrado para a aldeia.
} 
Nesse sentido, trazem para o filme um dos questionamentos originais do grupo: o que queremos mostrar aos de fora? A outra experiência aconteceu no ano seguinte, em 2019 com os Anacé, conforme elucidaremos a seguir.

\section{Encontros em Taba dos Anacé}

A formação e a produção do filme Taba dos Anacé, realizado em janeiro de 2019, partiu de uma demanda semelhante à de Uma aldeia Chamada Viração, ou seja, aconteceu no contexto de uma Assembleia da Juventude Indígena do Estado do Ceará, ocorrida na reserva indígena Taba dos Anacé. Julgamos, à vista disso, ser necessário contextualizar brevemente como tomamos conhecimento das questões que envolvem o povo da reserva Anacé. Nosso primeiro contato com as questões dessa reserva se deu por intermédio da pesquisadora Rute Moraes Souza, do povo Anacé, que aborda a remoção de seu povo das aldeias Matões e Bolso por conta do Complexo Industrial Portuário do Pecém (CIPP ${ }^{4}$ ), em um processo de conflito que perdura desde o ano de 1996. De acordo com a pesquisadora,

[o] processo de implantação e expansão do CIPP representa o crescimento e 'desenvolvimento' do Governo Federal, estando em disputa com a mobilização Anacé, junto com os órgãos indigenistas. O complexo Industrial localiza-se no limite entre o município de Caucaia e São Gonçalo do Amarante, área metropolitana de Fortaleza, aproximadamente a $3 \mathrm{~km}$ da aldeia Matões, provocando impactos, que envolvem diretamente a população tradicional residente e adjacente (SOUZA, 2019, p. 45).

Tal conflito recorrente entre interesses do governo e do povo indígena, por seu turno, levou posteriormente à remoção das duas aldeias, as quais acabaram sendo redirecionadas para uma reserva construída pelo Governo do Estado como compensação irrisória pelo dano causado ao povo Anacé. Souza descreve o processo:

Em 2014 tem início a concretização da construção da Reserva Indígena Taba dos Anacé. Todo o processo de desterritorialização, tristeza, e angústia se inicia novamente. Até então, a expectativa girava em torno das condições de vida e adaptação à nova vida na reserva, sem se saber se a nova terra seria boa para plantação de árvores que dão frutos como na antiga morada. Afinal, como saber se não se tem vivência com o novo ambiente de morada? A terra tradicional continua sendo, pelo menos por agora, aquela que vivemos a vida toda, pois para se adaptar ao novo lugar levará

\footnotetext{
${ }^{4}$ Criado por Decreto da Assembleia Legislativa do Ceará e sancionado pela Lei estadual no 12.536/95, o Complexo Industrial Portuário do Pecém (anteriormente Companhia de Integração Portuária do Ceará - Cearáportos) é uma sociedade de economia mista pertencente à Administração Indireta do Governo do Ceará.
} 
tempo até que se possa 'replantar' e 'refazer' as referências que acionam costumes e tradições (SOUZA, 2019, p. 48).

Nesse contexto aconteceu a formação audiovisual dos Anacé, isto é, a proposta foi ofertada na Taba quando fazia menos de um ano que as famílias haviam sido retiradas das aldeias de Matões e Bolsões e realocadas em seu novo lar. Quando nos reunimos para discutir a temática dos exercícios de filmagem, a turma (adolescentes e adultos jovens) elegeu como temática principal documentar e discutir a condição de vida que Ihes foi imposta naquele momento histórico de acomodação na reserva, como também o processo de desterritorialização.

Assim, as formações foram organizadas tendo por base as experiências acumuladas a partir das ações práticas e das reflexões implementadas nos trabalhos da aldeia Viração. O momento que vivíamos nos fornecia informações e ampliava o nosso olhar para as experiências formativas com audiovisual e identidade indígena. No caso específico, uma diferença que percebemos foi a facilidade de escolha da temática pelos alunos Anacé, que supomos ter ligação direta com o momento que estavam vivendo, conforme citado anteriormente.

Como acontece em nossas formações, inicialmente realizamos os trabalhos de exercícios práticos que envolvem domínios do uso de câmera, microfone e tripé. Paralelo a esses trabalhos, efetuamos também os exercícios teóricos com noções de cinema e vídeo. De posse dessas noções, os alunos já começaram a questionar os moradores da Taba sobre a questão da remoção e de como se sentiam em não poder voltar mais para as casas que viviam em um momento anterior.

Ao contrário do que aconteceu em Uma Aldeia Chamada Viração, o vídeo dos Anacé não tinha apenas uma pessoa coordenando, mas sim um coletivo. Atribuímos esse fato às discordâncias do grupo no que se refere às vantagens e desvantagens quanto à realocação de seu povo. Isso também foi algo que se refletiu nas escolhas das perguntas das entrevistas. Não havia consenso sobre as mudanças que estavam vivendo: uma parte do povo achava a remoção negativa, por não verem a Taba como seu território tradicional, e a outra parte, mesmo vendo a remoção como algo ruim, enxergam na Taba uma esperança de não serem mais agredidos pelo Estado, tendo a limitação da terra finalmente respeitada.

No filme dos Anacé, assim como no da Aldeia Viração, também há um momento muito claro de ficcionalização documental, onde Gleidson Anacé aparece fazendo tinta com amigos e conversando sobre o que é ser indígena na universidade, isto é, fora da aldeia. Num depoimento do filme ele afirma: "Quando entrei na faculdade (...) a criatura 
perguntou se eu tinha carteira para provar que era índio, e eu perguntei se ele tinha carteira para provar que era branco" (TABA DOS ANACÉ, 2019).

Esse aspecto dos depoimentos pode caracterizar Taba dos Anacé como um vídeo engajado politicamente, porém não mais do que Uma aldeia Chamada Viração. Entretanto, é possível afirmar que o primeiro possui maior intencionalidade, por tratar de maneira muito direta os temores e desejos de seus realizadores, sobretudo em relação às mudanças vividas pelos Anacé, indo além da missão de registrar o cotidiano da aldeia, afirmando-se, desse modo, como um vídeo manifesto daquele momento na vida dos jovens Anacé, bem como das lutas pela afirmação cultural e étnica (PORTO, 2017).

Nas reflexões que elaboramos no decorrer da pesquisa, consideramos as ideias e os processos de Zanetti (2010) e Andrade (2013), destacando principalmente as perspectivas de Daniela Zanetti sobre cinema da periferia, onde a autora apresenta narrativas do cotidiano, bem como discute a visibilidade e o reconhecimento social dessas narrativas.

Zanetti (2010) utiliza, nessa direção, o audiovisual como instrumento de produção a serviço de um discurso com um posicionamento político para atingir a esfera pública. Nesse sentido, atribui, ao fazer do cinema de periferia, outras possibilidades que estão para além de se auto-representar, de representar a própria realidade, ou de criar novas representações do mundo. Faz do audiovisual um instrumento de produção discursiva e de posicionamento, defendendo o valor político do ato de desenvolver produtos audiovisuais, "a partir de diferentes perspectivas culturais" e reconhecendo, como uma particularidade dessas produções, o fato de serem engajadas numa determinada causa "que tem relação direta com o lugar de onde fala" (ZANETTI, 2010, p. 74), bem como com os seus protagonistas, sendo este também o caso de nossa produção com os Anacé.

Ademais, o filme é um produto, mas também é um processo de etnografia da identidade de seus realizadores que, durante o processo, questionam-se e fortalecem não somente a si, mas aos seus respectivos povos, com quem têm contato direto durante a elaboração do projeto audiovisual. É possível perceber, desse modo, que "a questão da identidade guarda uma dimensão individual, mas também uma dimensão social" (ZANETTI, 2010, p. 103). Tal questão é, portanto, fruto de uma racionalidade que é revelada como algo a ser inventado e não a ser descoberto, resultando, pois, de um esforço de 'objetivo'. 


\section{Considerações finais}

Ao longo deste artigo, relatamos nossa experiência com a produção de audiovisual em duas comunidades indígenas. Nestas considerações finais, é importante tecer algumas reflexões sobre os processos e os produtos que resultaram das duas formações. A primeira delas é reforçar a ideia de que é possível se fazer cinema e produções audiovisuais como parte da luta pela afirmação das culturas dos povos indígenas do Ceará. A segunda diz respeito aos aspectos práticos do campo da visibilidade dos discursos produzidos em tais formações.

As duas produções obtiveram resultados bastante interessantes em suas exibições nos diferentes espaços, desde a mostra na aldeia até a sua exibição em circuitos culturais e acadêmicos. Foi muito gratificante perceber a forma como o público reage e fica fascinado pela história dos potiguara da Viração, como também fica indignado com os ataques sofridos pelo povo Anacé da Taba.

O presente trabalho focalizou processos de formação e suas singularidades, das quais destacamos a maneira como os alunos de ambos os povos tinham, em seus filmes, a ideia de um produto fílmico, para ser visto dentro da aldeia e também fora dela.

A experiência de serem realizadores fortaleceu as turmas que participaram da formação, sobretudo no que se refere às suas identidades. Tal fato fica evidenciado no caso de Letícia Potyguara que, ao assumir a direção de um filme, virou, ainda adolescente, uma pesquisadora da história de seu povo; e de Gleidson Anacé que usa do vídeo para expressar seus questionamentos quanto ao apagamento étnico e aos ataques sofridos por seu povo. Com isso, ressaltamos a importância do uso do audiovisual junto aos povos indígenas como instrumento de fortalecimento da memória, educação política e diálogo com a comunidade.

Relatar a experiência com esses dois povos se justifica, não apenas na perspectiva do fortalecimento da luta dos povos indígenas no Ceará, mas especialmente como exemplo a ser seguido por outros povos que possam estar em busca de sua afirmação étnica. Representa, dessa forma, mais uma possibilidade, tanto do ponto de vista prático, como teórico, sobre ensino de cinema e vídeo ${ }^{5}$ nos processos de fortalecimento étnico.

Como educadores, podemos dizer que as experiências vividas e refletidas nas duas formações nos levaram à aprendizagem e ao amadurecimento em relação às trajetórias

\footnotetext{
${ }^{5}$ Neste trabalho, diferenciamos cinema de vídeo. Pensamos os dois como parte da linguagem audiovisual, já que, dentro das possibilidades do Cinema Indígena, o vídeo é muito mais acessível como plataforma.
} 
dos povos. Aprendemos com as lideranças, com os alunos, com a comunidade, e são essas aprendizagens que vão moldando nosso trabalho e nossa visão de mundo. Destacamos principalmente as aprendizagens com os jovens realizadores, os quais nos ajudaram a construir estratégias e nos fizeram perceber que eles próprios poderiam criar e recriar suas visões individuais e coletivas acerca de identidades étnicas. Esse processo nos levou a uma reflexão sobre como podemos, de fato, olhar nossas questões étnicas na cultura brasileira e na sua relação com o que aprendemos na escola sobre nossa história e memória familiar.

Em suma, as duas experiências reforçaram a necessidade de um olhar atento para a juventude indígena do Ceará. Trata-se de jovens que, mesmo de forma precária, mantêm contato com o mundo das redes sociais, e ainda vivem os conflitos inerentes ao fato de serem indígenas no Brasil. Dessas observações atentas, percebemos que a educação dentro da aldeia passa pelo ideal de crescimento pessoal, e que, para alguns indivíduos, pode ir além dos traumas coletivos dos povos, das ameaças e das lutas.

Dado nosso histórico de luta social, seria muito cômodo, para nós, termos partido para uma abordagem que levasse os alunos a realizarem uma produção de filmes focada apenas no protesto. Contudo, preferimos investir num trabalho que envolvesse cultura, etnia e autorreconhecimento, de uma forma horizontal, onde todos nós aprendemos juntos e podemos desse modo reelaborar os nossos discursos. Com essa postura, permitimos que o pensamento indígena e o modo de fazer da aldeia fosse a nossa pedagogia. Por meio desse viés que tem, em sua essência, a filosofia educacional de Paulo Freire, colocamonos na posição de aprendizes. Assim, apesar de havermos finalizado as duas experiências, elas continuam vivas em nós e ainda são objetos de reflexões quando as retornamos e quando revemos o material audiovisual que produzimos.

\section{Referências}

ANDRADE, M. H. M. O ato narrativo audiovisual e a inclusão digital: concepções e perspectivas por jovens de periferia. Dissertação (Programa de Pós-Graduação em Educação Matemática e Tecnológica). Universidade Federal de Pernambuco. Recife, 2013.

ARAÚJO, J. J. Práticas fílmicas do Projeto Vídeo nas Aldeias. Fortaleza: Passagens: Revista do Programa de Pós-graduação em Comunicação - UFC, v. 5, n. 2, 2014. p. 20-40.

BARTOLOMÉ, M. A. As etnogêneses: velhos atores e novos papéis no cenário cultural e político. Rio de Janeiro: Mana, v. 12. n. 1, 2006. Disponível em: <http://www.scielo.br/scielo.php?script=sci_arttext\&pid=S0104-93132006000100002\& Ing=pt\&tlng=pt>. Acesso em: 11 fev. 2021. 
BOSI, A. Plural, mas não caótico. In: BOSI, A. Cultura brasileira: temas e situações. São Paulo: Ática, 1992.

BRAGA, M. A. Identidade étnica e os índios no Brasil. Caxias do Sul: MÉTIS: história \& cultura, v. 4, n. 7, 2005. p. 197-212. Disponível em: <http://www.ucs.br/etc/revistas/index.php/metis/article/view/1178>. Acesso em: 04 out. 2020.

COSTA, G. M.; GALINDO, D. Produção Audiovisual no contexto dos povos indígenas: Transbordamentos estéticos e políticos. In: DELGADO, P. S.; JESUS, N. T. Povos Indígenas do Brasil: Perspectivas no Fortalecimento de Lutas e combate ao preconceito por meio do audiovisual. Curitiba: Brasil Publishing, 2018, p. 21-50.

COSTA, R. S. Um pintor holandês no Novo Mundo: os tipos brasileiros de Albert Eckhout e a glorificação de Maurício de Nassau. Porto Alegre: Revista-Valise, v. 1, n. 2, ano 1, 2011. Disponível em: <https://seer.ufrgs.br/RevistaValise/article/view/19673/14534>. Acesso em: 03 out. 2020.

FREIRE, P. Pedagogia da Esperança - Um reencontro com a pedagogia do oprimido. São Paulo: Editora Paz e Terra. 2020.

HALL, S. A identidade cultural na pós-modernidade. Rio de Janeiro: 12. ed, Editora Lamparina, 2015. 58p.

HOBSBAWM, E.J. Introdução: A invenção das tradições. In.: HOBSBAWN, Eric; RANGER, Terence (org.). A invenção das tradições. Rio de Janeiro: Rio de Janeiro: Paz e Terra, 2008.

KRENAK, A. Coleção Tembetá de pensadores indígenas. Rio de Janeiro: Beco do Azougue Editorial Ltda, 2017.

LYRA, B. Cinema e audiovisual: cinco anotações. Revista da Associação Nacional dos Programas de Pós-Graduação em Comunicação. Brasília, 2005. Disponível em: <https://www.e-compos.org.br/e-compos/article/view/49>. Acesso em: 05 out. 2020.

NUNES, K. M.; SILVA I.; SILVA R. O. S. Cinema indígena: de objeto sujeito da produção cinematográfica no Brasil. Chile: Polis [online], v. 13, n. 38, 2014, p. 173-204. Disponível em: <https://scielo.conicyt.cl/scielo.php?script=sci_abstract\&pid=S071865682014000200009\&ln g=es\&nrm=iso\&tlng=pt>. Acesso em: 12 fev. 2021.

PORTO, A. C. M. Y'hovy ohechaárami: oficinas de cinema na Tekoha Y'hovy. Dissertação (Pós-Graduação em Antropologia, Setor de Ciências Humanas). Universidade Federal do Paraná. Curitiba, 2017.

POVOS INDÍGENAS NO BRASIL. Taba dos Anacé (Povo Anacé 2019) - Documentário. Disponível em: <https://www.youtube.com/watch?v=XgYLFyZAELw>. Acesso em: 06 mar. 2021.

RIBEIRO, D. As américas e a civilização, estudos de antropologia da civilização. Petrópolis: Editora Vozes, 1979. 580p.

SANT'ANA, M. F. T. Cena de Caminhada e da Conversação do Cinema Mbyá-Guarani. In: DELGADO, P. S.; JESUS, N. T. Povos Indígenas do Brasil: Perspectivas no Fortalecimento de Lutas e combate ao preconceito por meio do audiovisual. Curitiba: Brasil Publishing, 2018, p. 51-80.

SILVA, J. G. O índio no Cinema Brasileiro. Curitiba: Monstro dos Mares, 2020. 158p. 
SOUZA, R. M. Tabas Roças e Lugares de Encanto: Construção e Reconstrução Anacé em Matões, Caucaia, Ceará. Monografia. Bacharelado em Ciências Sociais. Universidade Federal do Recôncavo Baiano. Cachoeria, 2019.

UMA ALDEIA CHAMADA VIRAÇÃO (2018). Documentário disponível em: <https://www.youtube.com/watch?v=emwAzpBUM2w>. Acesso em: 06 mar. 21.

WERÃ, K. Coleção Tembetá de pensadores indígenas - Kaka Werã. Rio de Janeiro: Beco do Azougue Editorial Ltda, 2019. 143p.

ZANETTI, D. O cinema da periferia: Narrativas do cotidiano, visibilidade e reconhecimento social. 319f. Dissertação (Pós-Graduação em Comunicação e Cultura). Universidade Federal da Bahia. Salvador, 2010.

i Mestrando em Artes no PPGArtes do Instituto Federal do Ceará (IFCE). Graduado em Áudio Visual e Novas Mídias pela Universidade de Fortaleza (UNIFOR). Professor da Escola de Cinema Indígena Jenipapo-Kanindé.

ii Doutor em História pela Universidade Federal de Pernambuco (UFPE), com pós-doutorado na Universidade do Porto, Portugal. Professor do Programa de Pós-Graduação em Educação da Universidade Estadual do Ceará (UECE) e do PPGArtes do Instituto Federal do Ceará (IFCE).

Como citar esse artigo:

SOARES, Iago Barreto; SALES, José Albio Moreira. Formação audiovisual e identidade indígena na produção de cinema e vídeo com os povos Potiguara e Anacé. Revista Digital do LAV, Santa Maria: UFSM, v. 14, n. 1, p. 103-120, jan./abr. 2021. 